\title{
Capillary convection in pulsed - butt welding of miscible dissimilar couple
}

\author{
Yaowu Hu', Xiuli He', Gang Yu' and Shusen Zhao
}

(9SAGE

\begin{abstract}
Pulsed laser butt welding of miscible dissimilar couple has been studied numerically based on a three-dimensional heat and mass transfer model. Driving forces of molten metal flow in the case of stainless steel and nickel are compared using dimensional analysis. Thermo-capillary convection due to surface temperature gradient is recognized as the dominating fluid flow. Temperature coefficients of surface tensions are varied to investigate the influences of the convection on heat and mass transfer phenomena in weld pool. The temperature fields at stainless steel and nickel sides are found to be asymmetric and are greatly affected by different Marangoni convections. Concentration of Ni increases as the temperature coefficient of surface tensions changes from negative to positive. The temperature coefficient of surface tension of stainless steel has greater impact on the weld pool configuration and element concentration than that of nickel. The obtained weld pool configurations are found to be dependent on Prandtl number and convection patterns.
\end{abstract}

\author{
Keywords \\ Laser welding, dissimilar, Marangoni convection, heat transfer, weld pool
}

Date received: 5 August 2015; accepted: 5 February 2016

\section{Introduction}

Joining of dissimilar materials is often desired in various industrial applications including aerospace, automotive, marine, rail, and biomedical devices by providing greater flexibility in material selection and structural design, enhancing mechanical robustness and multifunctionalities with integrated properties from individual components, and lowering manufacturing costs by tailoring expensive materials use. ${ }^{1-3}$ However, it is typically accompanied with technical challenges, because of chemical or physical property mismatch of the two materials involved, resulting in difficulties in microstructure prediction, fusion zone control, and insufficient weld penetration. Intermetallic compounds which are typically brittle would form at dissimilar metal joints, resulting from excessive solute dilution and inappropriate temperature evolution. ${ }^{2-10}$ A deep understanding of heat transfer in fusion welding of dissimilar couples is thus of crucial importance to advance the technology for future commercial use.

High power density lasers have attracted intense research interest in various areas of advanced manufacturing ${ }^{11-22}$ due to their high efficient, precise, and flexible material-processing features. The transport phenomena during laser-matter interaction is the key for their implementations. In the area of welding, analytical modeling and numerical simulations on same metal welding have been carried out to study heat input, temperature profiles and cooling rates, and gain insights of final microstructure, residual stress, structural distortion, and mechanical strength of the weldment. The first analytical model is by Rosenthal who treats the heat source to be point, line, and plane in predicting temperature. Since then, analytical models have been developed to incorporate more realistic heat input, specimen dimensions, moving heat source, and material phase change. ${ }^{23-26}$ However, the inherited limitations of this approach due to its oversimplification of the real fusion welding process make it difficult to use in dissimilar welding. Numerical simulations by solving heat conduction equations with hypothesized heat source model are widely used recently. The physical

\footnotetext{
'Key Laboratory of Mechanics in Advanced Manufacturing, Institute of Mechanics, Chinese Academy of Sciences, Beijing, People's Republic of China

${ }^{2}$ Laboratory of All-Solid-State Laser Sources, Institute of Semiconductors, Chinese Academy of Sciences, Beijing, People's Republic of China

\section{Corresponding authors:}

Xiuli He, Key Laboratory of Mechanics in Advanced Manufacturing, Institute of Mechanics, Chinese Academy of Sciences, Beijing 100190, People's Republic of China. Email: xlhe@imech.ac.cn

Gang Yu, Key Laboratory of Mechanics in Advanced Manufacturing, Institute of Mechanics, Chinese Academy of Sciences, Beijing 100190, People's Republic of China.

Email: gyu@imech.ac.cn
} 
soundness of the proposed heat source models is validated by matching calculations with measured temperatures or fusion zone boundaries, ${ }^{27-34}$ parameters which are in fact difficult to measure, given that high temperature (several thousand Kevin), short process time $(\sim \mathrm{ms})$, and small welding spot $(\sim \mu \mathrm{m})$ are present in the case of laser welding. Furthermore, the hypothesized models, even could provide consistent temperature predictions with experimental measurements at limited locations, may in fact give inaccurate calculations inside laser spot. It is shown in $\mathrm{Hu}$ et al. ${ }^{35}$ that temperature fields outside of weld pool by two different models could be the same, but fields inside the weld pool are quite different. Thus a more realistic approach with weld pool fluid dynamics is essential for high-fidelity study of transport phenomena during fusion welding.

Weld pool convections have been under increasing research interest and mainly focused on couples with similar material properties. The temperature and flow field evolution during laser spot welding of stainless steel (SS) have been studied by He et al. ${ }^{36}$ Variations of surface tension of metals with temperature and surface active elements, such as sulfur and oxygen, have been investigated by Sahoo et al. ${ }^{37}$ Fluid-flow patterns and weld penetrations under different sulfur concentrations in gas tungsten arc (GTA) welding of SS have been theoretically studied by Wang et al. ${ }^{38}$ It was found that the weld shape and depth/width ratio depended to a large extent on the sulfur content of weld metal and Marangoni convection patterns. Similar results have also been obtained on oxygen in shielding gas for laser spot welding and GTA welding process. ${ }^{39,40}$ Progresses on welding of similar metals keep blooming. Welding of dissimilar couple, however, is still restricted to analytical or heat conduction-based models ${ }^{4,41-43}$ in predicting temperature fields. When two distinct materials are present, physical and thermal properties change as mass transport, making the aforementioned approaches significantly deviate from reality. Studies on heat and mass transfer during dissimilar metal welding have been quite limited. ${ }^{44} 48$ There is an urgent need to study driving forces for fluid flow and their influences on temperature field, mass distribution, and final fusion zone.

In this work, dimensional analysis and a transient three-dimensional model are employed together to study driving forces of fluid dynamics and transport phenomena in conduction mode laser spot welding of miscible dissimilar couple. Buoyancy effect, temperature, and concentration gradient-induced Marangoni effects are analyzed and compared. The effect of thermo-capillary convection on heat and mass transfer inside weld pool is then studied with varied temperature coefficient of surface tension. Experimentally obtained weld pool configurations in laser welding of $\mathrm{Ni}$ and SS are then compared with the corresponding calculations from the model. This work can provide in-depth knowledge to understand and harness fluid dynamics in dissimilar fusion welding.

\section{Mathematical modeling}

Pulsed laser butt welding of 304SS and Ni sheets, both sized $20 \times 10 \times 2 \mathrm{~mm}^{3}$, is schematically shown in Figure 1. The chemical composition of 304SS is given in Table 1. A full description of all mechanisms taken place during laser material interactions would result in the problem inextricable and is beyond the purpose of this work. For the sake of simplicity, laser is modeled as a Gaussian heat source irradiating at the center of the workpiece surface. Certain assumptions are made in order to simplify the calculations: the liquid/air interface is assumed to be flat; the molten metal is Newtonian and incompressible; the flow is laminar.

\section{Governing equations}

The simulation is based on the numerical solution of mass, momentum, energy, and species conservation relationship.

Continuity equation

$$
\nabla \cdot \vec{V}=0
$$

where $\mathbf{V}$ is the velocity vector.

Momentum equation

$$
\begin{aligned}
\frac{\partial \vec{V}}{\partial t}+(\vec{V} \cdot \nabla) \vec{V}= & -\frac{1}{\rho} \nabla P+v \nabla^{2} \vec{V}-K \vec{V} \\
& +\vec{g} \beta_{T}\left(T-T_{r e f}\right)+\vec{g} \beta_{C}\left(C-C_{r e f}\right)
\end{aligned}
$$

where $K=K_{0}\left(1-f_{l}\right)^{2} /\left(f_{l}^{3}+B\right)$

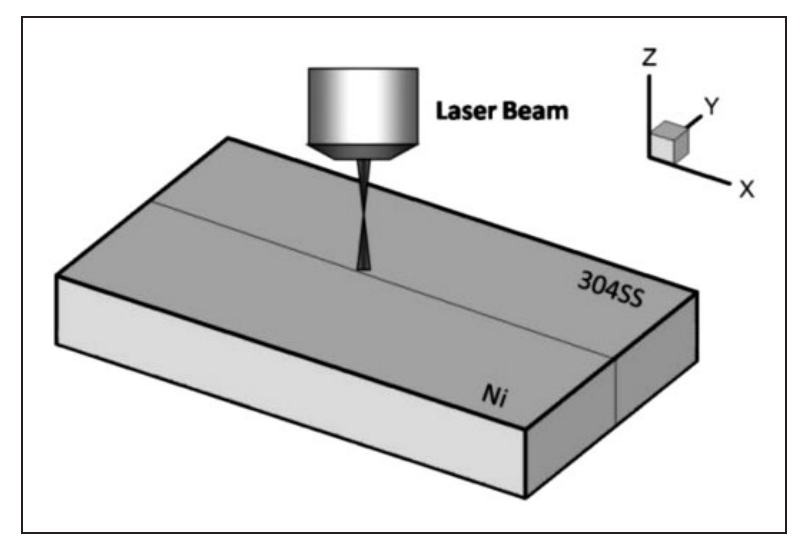

Figure I. Schematic of laser dissimilar butt welding.

Table I. Chemical composition of 304SS (atomic fraction (\%)).

\begin{tabular}{lllll}
\hline $\mathrm{Cr}$ & $\mathrm{Ni}$ & $\mathrm{Mn}$ & $\mathrm{Si}$ & $\mathrm{Fe}$ \\
\hline $\mathrm{I} 8.4$ & 8.5 & $\mathrm{I} .3$ & 0.8 & $\mathrm{Bal}$ \\
\hline
\end{tabular}


In Equation (2), $\rho$ is the fluid density, $P$ is the pressure, $v$ is the kinematic viscosity of the liquid phase, $K$ is the drag coefficient for a porous media model in the mushy zone. $\beta_{T}$ and $\beta_{C}$ are volumetric expansion coefficients due to temperature and concentration, respectively. $K_{0}$ is a constant representing the mushy zone morphology; $f_{l}$ is the liquid mass fraction; $B$ is a small positive number used to avoid the division by zero; $\mathbf{g}$ is gravitational acceleration. The last two terms account for buoyancy effects caused by temperature and concentration variations, respectively. The mass fraction of liquid is given by

$$
\begin{aligned}
& f_{l}=\frac{T_{n}-T_{s}}{T_{l}-T_{s}} \\
& T_{n}=\min \left(T_{l}, \max \left(T, T_{s}\right)\right)
\end{aligned}
$$

where $T_{s}$ and $T_{l}$ are the solidus and liquidus temperature, respectively.

Energy conservation equation

$$
\frac{\partial T}{\partial t}+\vec{V} \cdot \nabla T=\nabla \cdot\left(\frac{k}{\rho c} \nabla T\right)-\frac{\partial(\Delta H)}{\partial t}-\nabla \cdot(\vec{V} \Delta H)
$$

where $T$ is the temperature; $k$ is the thermal conductivity; $c$ is the specific heat. $\Delta H$ represents latent enthalpy for phase change in the computational cell. It is related to the liquid mass fraction according to the following equation

$$
\Delta H=L f_{l}
$$

where $L$ is the latent heat.

Species transport equation

$$
\begin{aligned}
\frac{\partial C}{\partial t}+\vec{V} \cdot \nabla C= & \nabla \cdot(D \nabla C)+\nabla \cdot\left(\rho D \nabla\left(C_{l}-C\right)\right) \\
& -\nabla \cdot\left(f_{s}\left(C_{l}-C_{s}\right) \vec{V}\right)
\end{aligned}
$$

where $C$ is the species concentration; $f_{s}$ is the solid mass fraction.

\section{Boundary conditions}

Laser irradiation is considered as a heat input at the top surface

$$
-k \frac{\partial T}{\partial z}=\frac{2 Q_{e}}{\pi r_{b}^{2}} \exp \left(-\frac{2 r^{2}}{r_{b}^{2}}\right)-h_{c}\left(T-T_{0}\right)-\sigma_{b} \varepsilon\left(T^{4}-T_{0}^{4}\right)
$$

where $Q_{e}$ is the absorbed laser power which depends on nominal laser output and absorption efficiency function of irradiated surface; $r$ is the distance from point of consideration to the center of laser beam; $r_{b}$ is effective radius of laser beam; $h_{c}$ is natural convection coefficient; $\sigma_{b}$ is StefanBoltzmann constant; $\varepsilon$ is the emissivity; $T_{0}$ is the environmental temperature. Heat loss due to thermal radiation and natural convection is considered. Isothermal boundary conditions are applied to the remaining surfaces.

The boundary condition for convection at the top surface is described by

$$
\rho \nu\left(\frac{\partial \vec{V}}{\partial z}-\widehat{n}\left(\widehat{n} \cdot \frac{\partial \vec{V}}{\partial z}\right)\right)=f_{l} \chi_{T} \nabla_{s} T+f_{l} \chi_{C} \nabla_{s} C
$$

where $\chi_{T}$ and $\chi_{C}$ are the temperature and composition coefficients of surface tension, respectively; $\hat{n}$ is a unit vector normal to the surface; $\nabla_{s}$ is the surface gradient operator. The two terms at the right-hand side in Equation (9) represent Marangoni convection, caused by Marangoni stress due to surface tension gradients by variation of temperature and composition, respectively. For the sake of simplicity, the surface tension $(\gamma)$ of the miscible metals is assumed to be linear function of elemental composition.

$$
\gamma=C \gamma_{1}+(1-C) \gamma_{2}
$$

With the above boundary conditions, a finite-volume method based on SIMPLEC algorithm is used to iteratively solve the governing equations. The non-uniform grid used for calculation is with $159 \times 160 \times 50$ meshes. The parameters used in simulation are presented in Table $2 .{ }^{35}$

\section{Results and discussion}

\section{Driving forces for molten metal dynamics}

The molten metal flow in the weld pool is mainly driven by two kinds of forces, namely buoyancy and Marangoni forces resulted from surface temperature or concentration gradients. Grashof number is the dimensionless number to describe the ratio of buoyancy force to viscous force. In the case of temperature variation, it is given by

$$
G r_{T}=\frac{g \beta_{T} L_{R}^{3} \Delta T \rho^{2}}{\mu^{2}}
$$

For concentration gradients, the expression is similar

$$
G r_{C}=\frac{g \beta_{C} L_{R}^{3} \Delta C \rho^{2}}{\mu^{2}}
$$

Surface tension Reynolds number, Ma, is used to describe the ratio of surface tension gradient force to viscous force. Marangoni convection due to temperature gradient is 
Table 2. Material properties used in the simulation.

\begin{tabular}{lll}
\hline Property/parameter & $304 \mathrm{SS}$ & $\mathrm{Ni}$ \\
\hline Density of liquid metal $\left(\mathrm{kg} \cdot \mathrm{m}^{-3}\right)$ & 7200 & 8880 \\
Dynamic viscosity $\left(\mathrm{kg} \cdot \mathrm{m}^{-1} \mathrm{~s}^{-1}\right)$ & $6.70 \times 10^{-3}$ & $3.68 \times 10^{-3}$ \\
Solidus temperature $(\mathrm{K})$ & 1672 & 1730 \\
Liquidus temperature $(\mathrm{K})$ & 1727 & 1735 \\
Thermal conductivity of solid $\left(\mathrm{W} \cdot \mathrm{m}^{-1} \mathrm{~K}-1\right)$ & 19.2 & 60.7 \\
Effective thermal conductivity of liquid $\left(\mathrm{W} \cdot \mathrm{m}^{-1} \mathrm{~K}^{-1}\right)$ & 50 & 150 \\
Specific heat of solid $\left(\mathrm{kg}-1 \cdot \mathrm{K}^{-1}\right)$ & 711.28 & 515 \\
Specific heat of liquid $\left(\mathrm{J} \cdot \mathrm{kg}^{-1} \cdot \mathrm{K}^{-1}\right)$ & 836.8 & 595 \\
Surface tension $\left(\mathrm{N} \cdot \mathrm{m}^{-1}\right)$ & 1.872 & 1.778 \\
Coefficient of thermal expansion $\left(\mathrm{K}^{-1}\right)$ & $1.96 \times 10^{-5}$ & $4.50 \times 10^{-5}$ \\
Latent heat $(\mathrm{kg}-1)$ & $2.72 \times 10^{5}$ & $2.9 \times 10^{5}$ \\
Effective mass diffusivity $\left(\mathrm{m}^{2} \mathrm{~s}^{-1}\right)$ & $7 \times 10^{-7}$ & $7 \times 10^{-7}$ \\
\hline
\end{tabular}

$$
M a_{T}=\frac{\rho C_{p} L_{R} \Delta T|\partial \gamma / \partial T|}{\mu k}
$$

where $L_{R}$ is the characteristic length and $\Delta T$ is the temperature interval between the peak temperature and melting point. Marangoni convection due to concentration gradient is

$$
M a_{C}=\frac{L_{R} \Delta C\left|\gamma_{c 1}-\gamma_{c 2}\right|}{\mu D}
$$

In the present investigation, with $\mathrm{L}_{\mathrm{R}}$ taken to be $1 \mathrm{~mm}, \Delta T$ taken to be $700 \mathrm{~K}$, and $\Delta C$ taken to be 0.1 , these dimensionless numbers are on the order of

$$
\begin{aligned}
& G r_{T}=O\left(10^{2}\right) \\
& G r_{C}=O\left(10^{2}\right) \\
& M a_{T}=O\left(10^{5}\right) \\
& M a_{C}=O\left(10^{3}\right)
\end{aligned}
$$

It can be expected that the liquid flow is mainly driven by Marangoni convection, and to a much less extent, by buoyancy effect. Furthermore, the relative value of surface tension Reynolds number $\left(\mathrm{Ma}_{\mathrm{T}}\right.$ and $\mathrm{Ma}_{\mathrm{C}}$ ) indicates that temperature gradient plays a more important role than concentration gradient in driving the fluid flow.

In order to describe the effects of temperature and concentration effects more clearly, the following stress terms could be defined

$$
\begin{aligned}
& \sigma_{T}=\nabla_{s u r} T \cdot \partial \gamma / \partial T \cdot f_{l} \\
& \sigma_{c}=\nabla_{s u r} C \cdot\left(\gamma_{c 1}-\gamma_{c 2}\right) \cdot f_{l}
\end{aligned}
$$

which represent interfacial stress due to temperature and concentration effects, respectively.
Figure 2 shows the calculated $\sigma_{\mathrm{C}}$ at various times. It should be noted that the maximum stress at the solid/liquid interface results from sharp discontinuity of element concentration in the molten pool and the substrate and is weak in driving the liquid metal flow due to closeness to the solid substrate. The stress inside the weld pool is on the order of $10^{2} \mathrm{~N} / \mathrm{m}^{2}$ initially and decreases quickly as the elements become mixed. This means Marangoni convection due to concentration gradient acts as a driving force for molten metal flow mainly during the initial stage.

Figure 3 shows the calculated $\sigma_{\mathrm{T}}$ at various times. If the sign of $\sigma_{\mathrm{T}}$ is negative, the fluid flows away the center of the weld pool, transporting heat from the center to the periphery of the weld pool. It could be seen that the maximum stress is on the order of $10^{2} \mathrm{~N} / \mathrm{m}^{2}$, which is comparable with $\sigma_{\mathrm{C}}$ at the initial stage. However, unlike $\sigma_{\mathrm{c}}, \sigma_{\mathrm{T}}$ does not decrease with time and tends to become steady as the weld pool develops. Thus after a short time of weld pool development, $\sigma_{\mathrm{T}}$ prevails and serves as the major driving force for heat and mass transport during laser welding of dissimilar materials.

\section{Thermo-capillary convection}

In the previous section, interfacial stress $\sigma_{\mathrm{T}}$ has been found to be the major driving force for fluid dynamics and heat transport, and thus thermo-capillary convection dominates in the weld pool. In this section, temperature coefficient of surface tension is varied, as shown in Table 3, to investigate its influence on heat and mass transfer in laser spot welding of SS-Ni dissimilar couple. The absolute value of surface tension temperature coefficent for SS and Ni is $4.3 \times 10^{-4} \mathrm{~N} / \mathrm{m} \cdot \mathrm{k}$ and $3.4 \times 10^{-4} \mathrm{~N} / \mathrm{m} \cdot \mathrm{k}$, respectively.

The temperature fields at top surface and cross section at $500 \mathrm{~ms}$, when laser is switched off, are shown in Figures 4 and 5, respectively. The contour values are in Kelvin. The temperature field is asymmetric due to large difference of thermal conductivity of SS and Ni. 


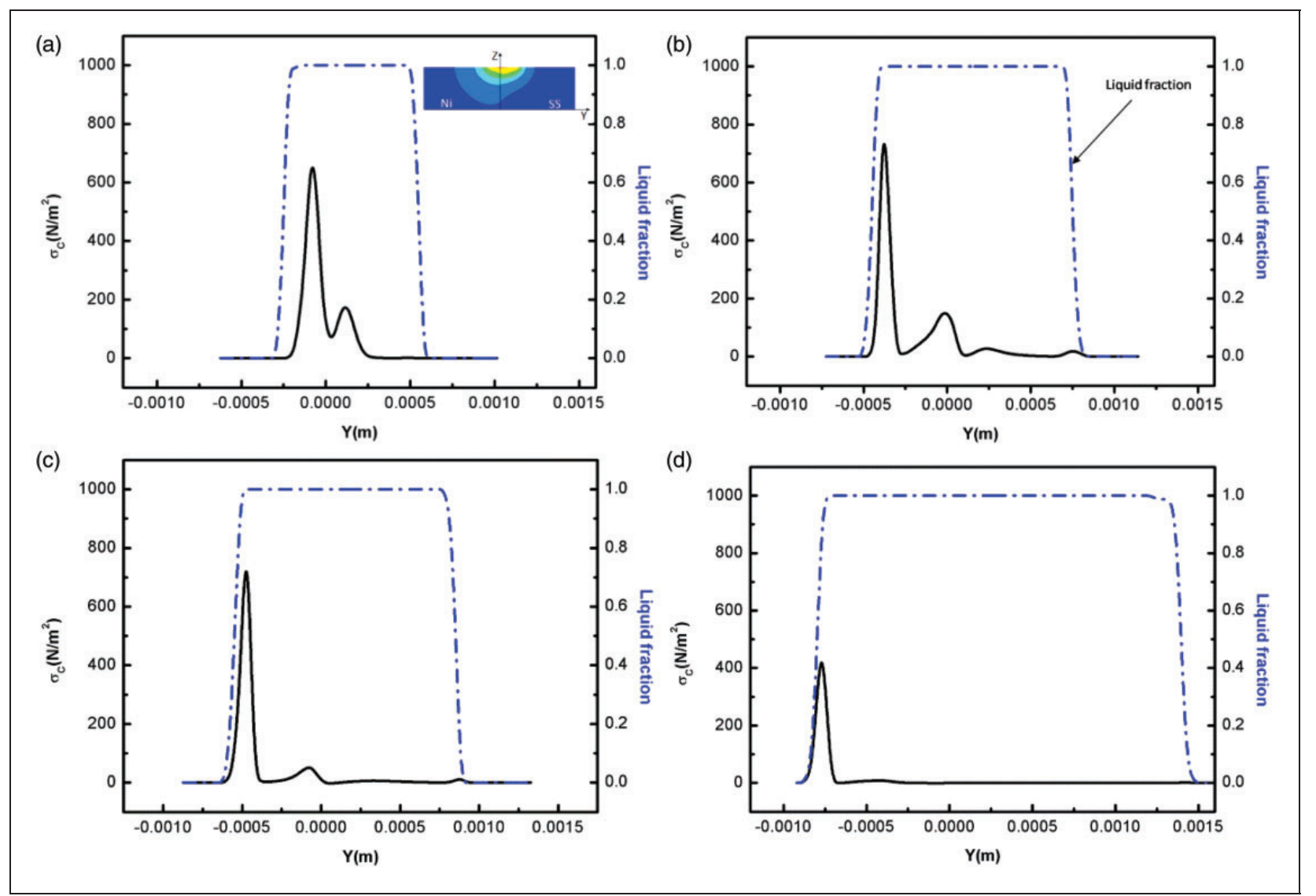

Figure 2. Marangoni stress due to concentration gradient $\left(\sigma_{c}\right)$ and liquid fraction at the time of (a) 10, (b) 30 , (c) 60, and (d) $500 \mathrm{~ms}$. Laser power: $650 \mathrm{~W}$; pulse duration: $500 \mathrm{~ms}$; spot diameter: $1.0 \mathrm{~mm}$.

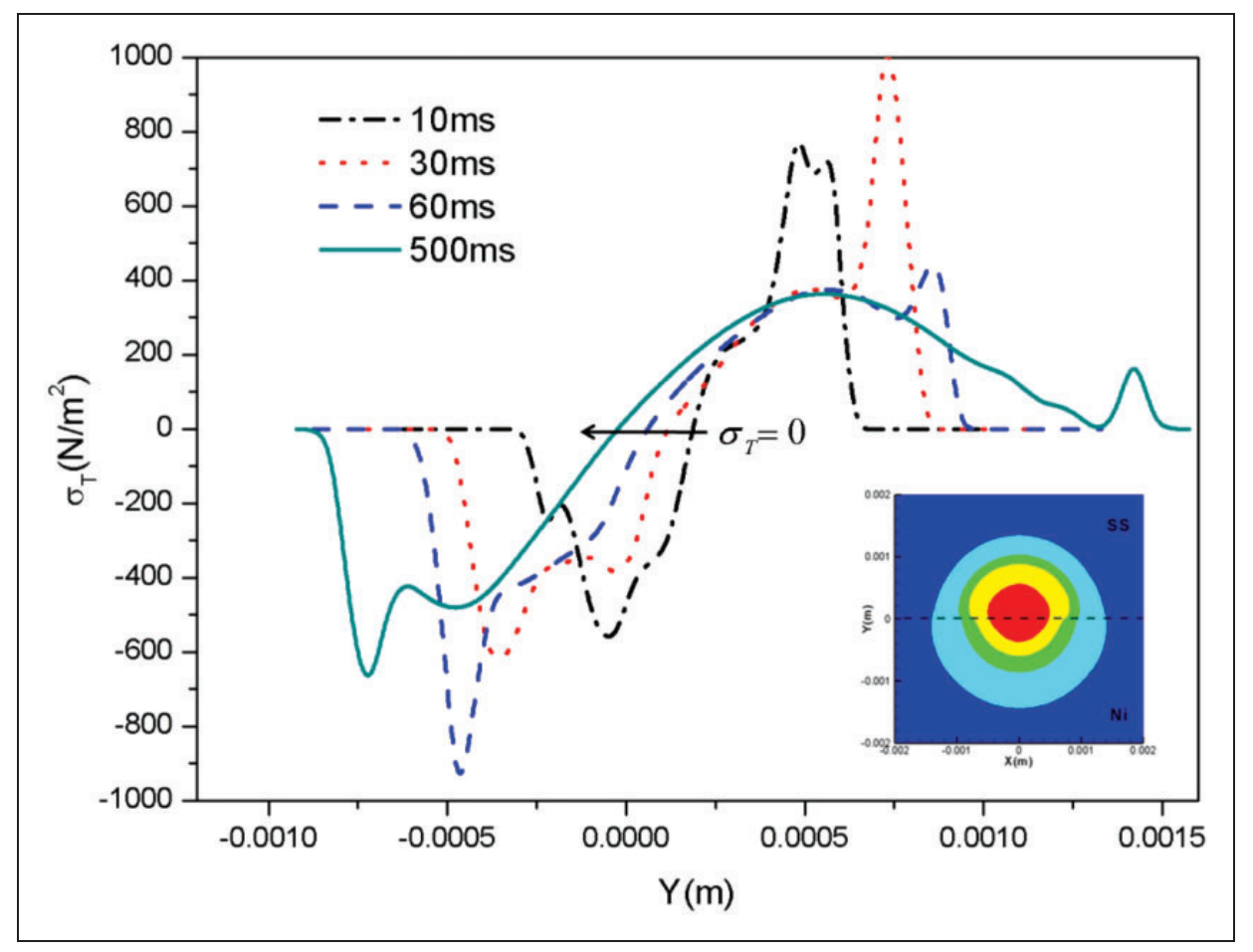

Figure 3. Marangoni stress due to temperature gradient $\left(\sigma_{T}\right)$ at various times. 
The weld pool dimension at the SS side is larger than that at the Ni side. The highest temperature is located near the center of the heat source $(0,0,2 \mathrm{~mm})$, where the zenith heat flux locates.

The temperature field and weld pool dimension vary as the temperature coefficient of surface tension changes and are found to mainly depend on the coefficient of SS. For case 3, the temperature coefficients of both metals are positive, thus the surface tension at the center of the weld pool will be larger than that at

Table 3. Case study by varying the sign of temperature coefficient of surface tension.

\begin{tabular}{lll}
\hline & $304 S S$ & $\mathrm{Ni}$ \\
\hline Case 1 & - & - \\
Case 2 & - & + \\
Case 3 & + & + \\
Case 4 & + & - \\
\hline
\end{tabular}

the periphery, driving the fluid flows from the periphery of the weld pool to the interior. The fluid changes its direction at the origin and goes downward, transporting heat deep into the interior part of the workpiece. Thus a deep and narrow weld pool is obtained under this kind of convection. On the contrary, for case 1 , the temperature coefficients of surface tension of both metals are negative. The molten metal flows from the interior of the weld pool to the periphery. The flow at the top surface enhances heat transport there and results in a wide and shallow weld pool. The calculated results also show that the temperature coefficient of $\mathrm{Ni}$ has weaker influence on the temperature fields. And results from cases 1 and 2 (cases 3 and 4) are very similar.

Figure 6 compares the temperature distribution of four cases for top surface and cross section. It is found that the temperature gradient at the top surface for cases 1 and 2 is lower than that for cases 3 and 4, especially at SS side, while the temperature gradient along cross section for cases 1 and 2 is higher than
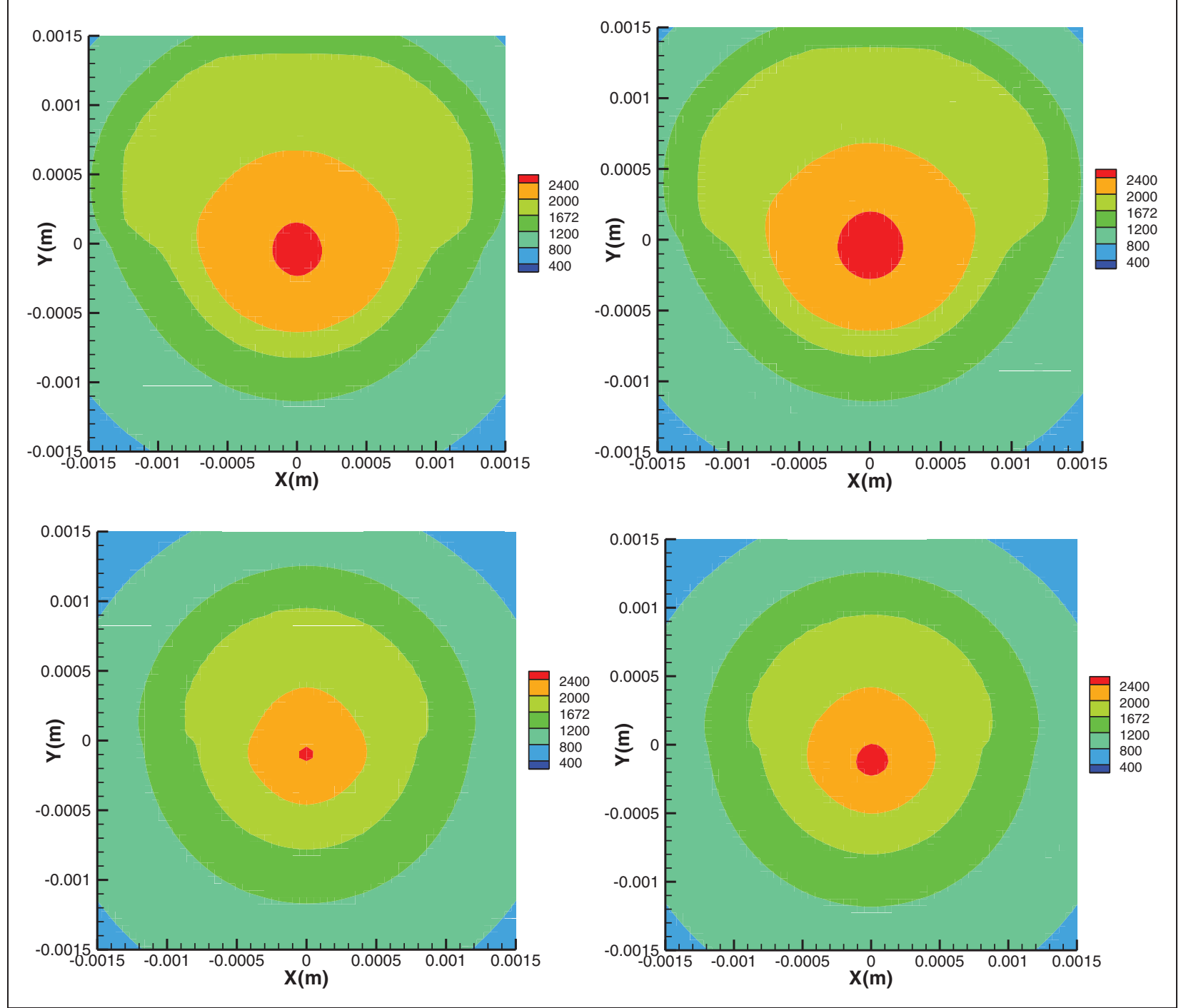

Figure 4. Temperature field at top surface at $500 \mathrm{~ms}$. (a) Case I, (b) Case 2, (c) Case 3, (d) Case 4. 


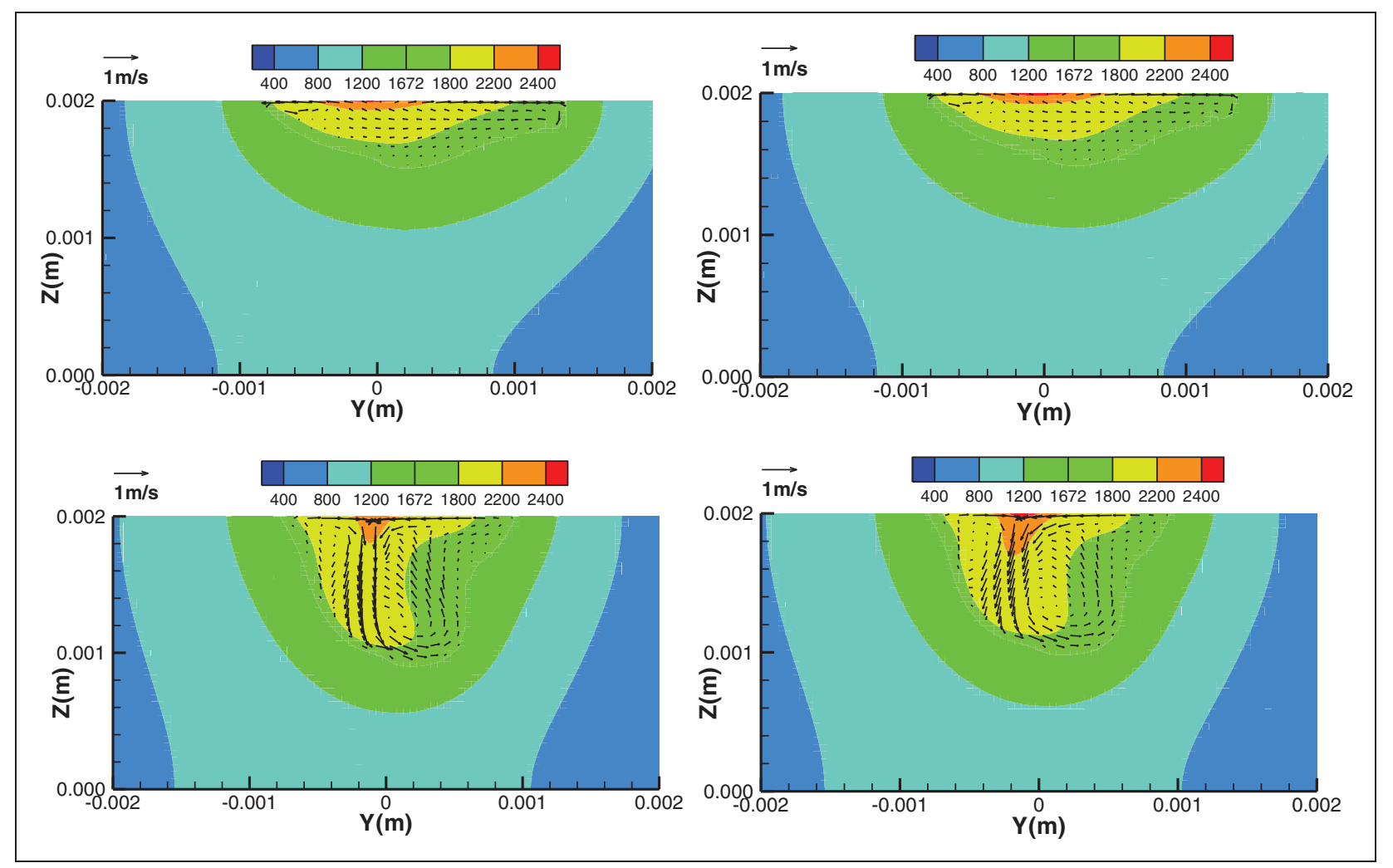

Figure 5. Temperature field along cross section $(x=0)$ at $500 \mathrm{~ms}$. (a) Case I, (b) Case 2, (c) Case 3, (d) Case 4.

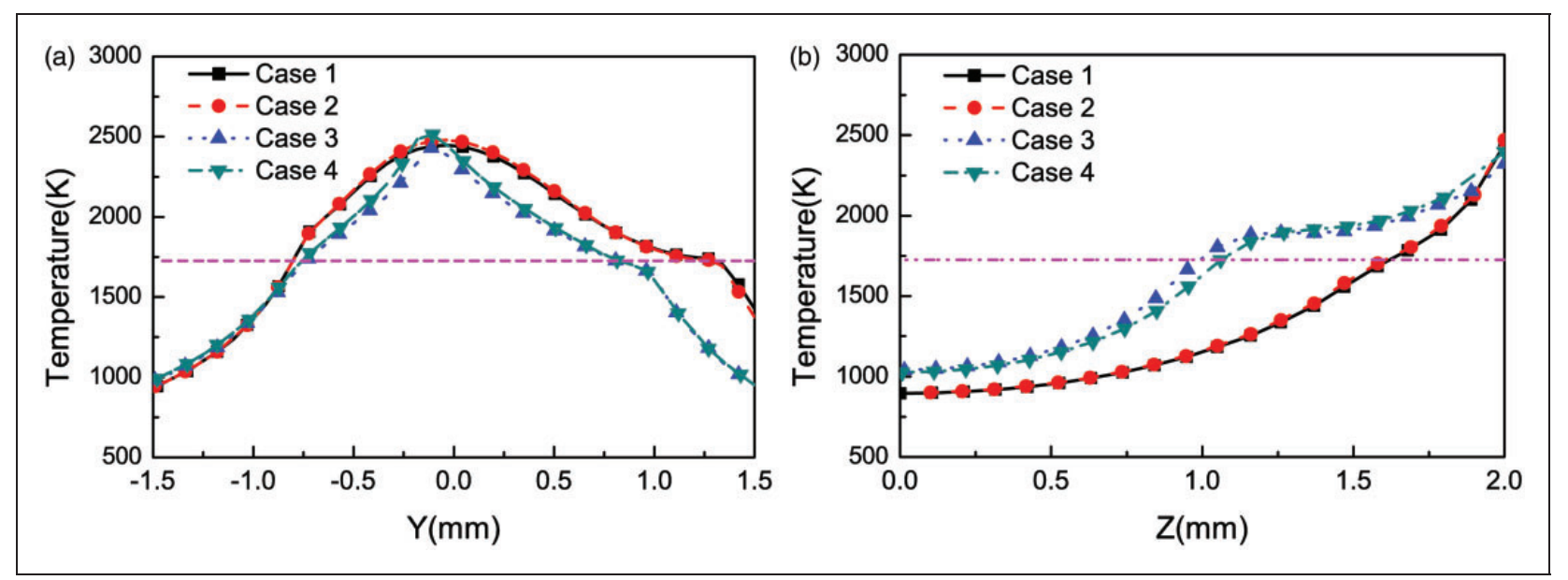

Figure 6. Temperature distribution at $500 \mathrm{~ms}$ (a) at top surface (b) along cross section.

that for cases 3 and 4 . These could be explained by different patterns of Marangoni convection. For cases 3 and 4 , the downward fluid flow transports heat from the center of heat source (high temperature area) to the bottom of weld pool (low temperature area), resulting in a low temperature gradient at the vertical direction. On the contrary, the outward fluid flow for cases 1 and 2 mainly transports heat in the horizontal direction and results in smooth temperature change in that direction. Heat convection becomes especially important for SS because of its low thermal conductivity. This demonstrates the importance of Marangoni convection on heat transport in the weld pool.
Figure 7(a) and (b) shows the calculated threedimensional temperature field and fluid flow for negative (case 1) and positive (case 3) temperature coefficient of surface tension, respectively. The half domain could be taken because the calculated results are symmetrical at $\mathrm{x}=0$ under laser spot welding. The weld pool and convections under different temperature coefficients are obviously different.

The concentration profiles of $\mathrm{Ni}$ at the top surface are shown in Figure 8. Elements for four cases are almost uniformly mixed in the weld pool. The concentration of $\mathrm{Ni}$ in the weld pool is less than 0.5 . Since the surface tension in the weld pool is assumed to be 


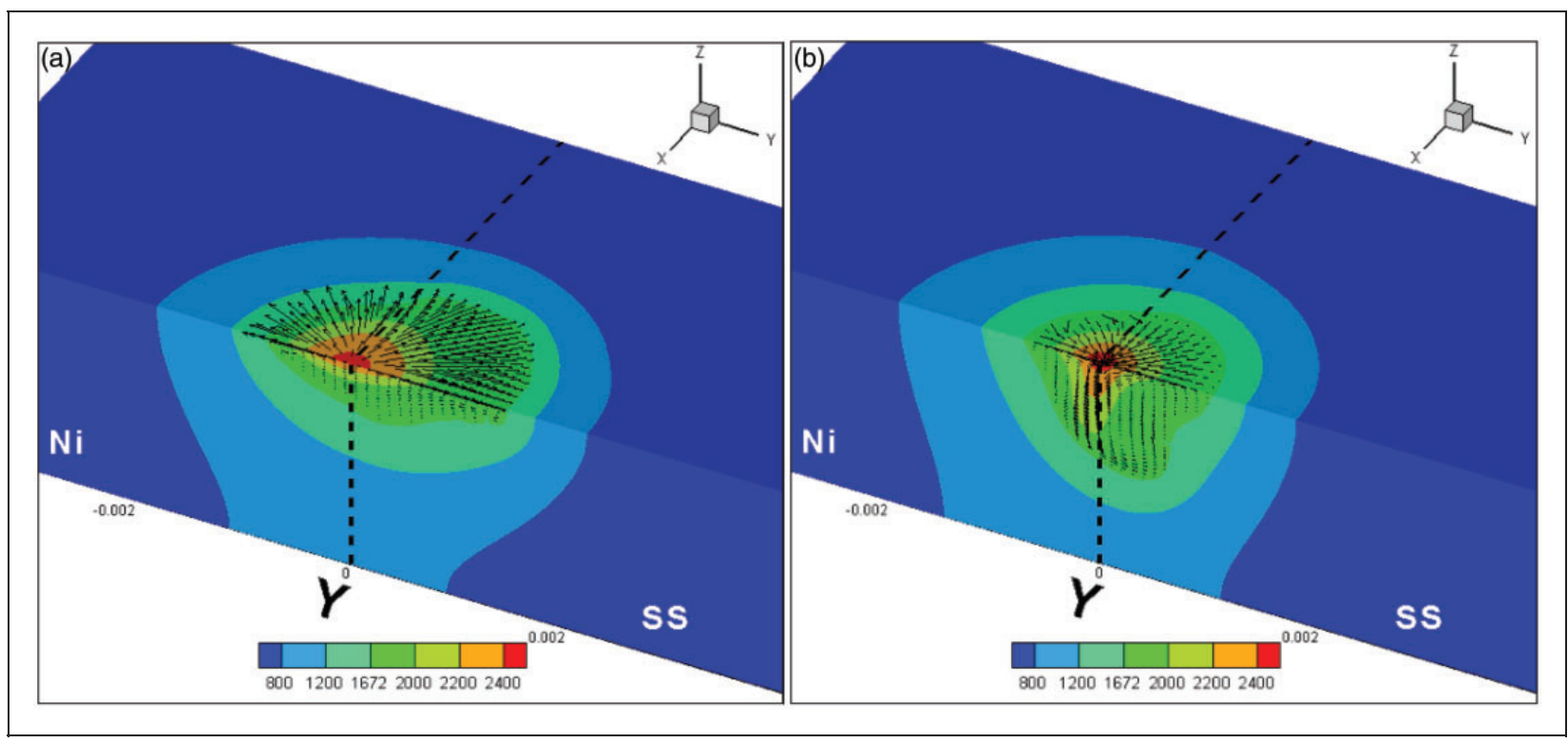

Figure 7. Calculated temperature field with (a) negative and (b) positive temperature coefficient.

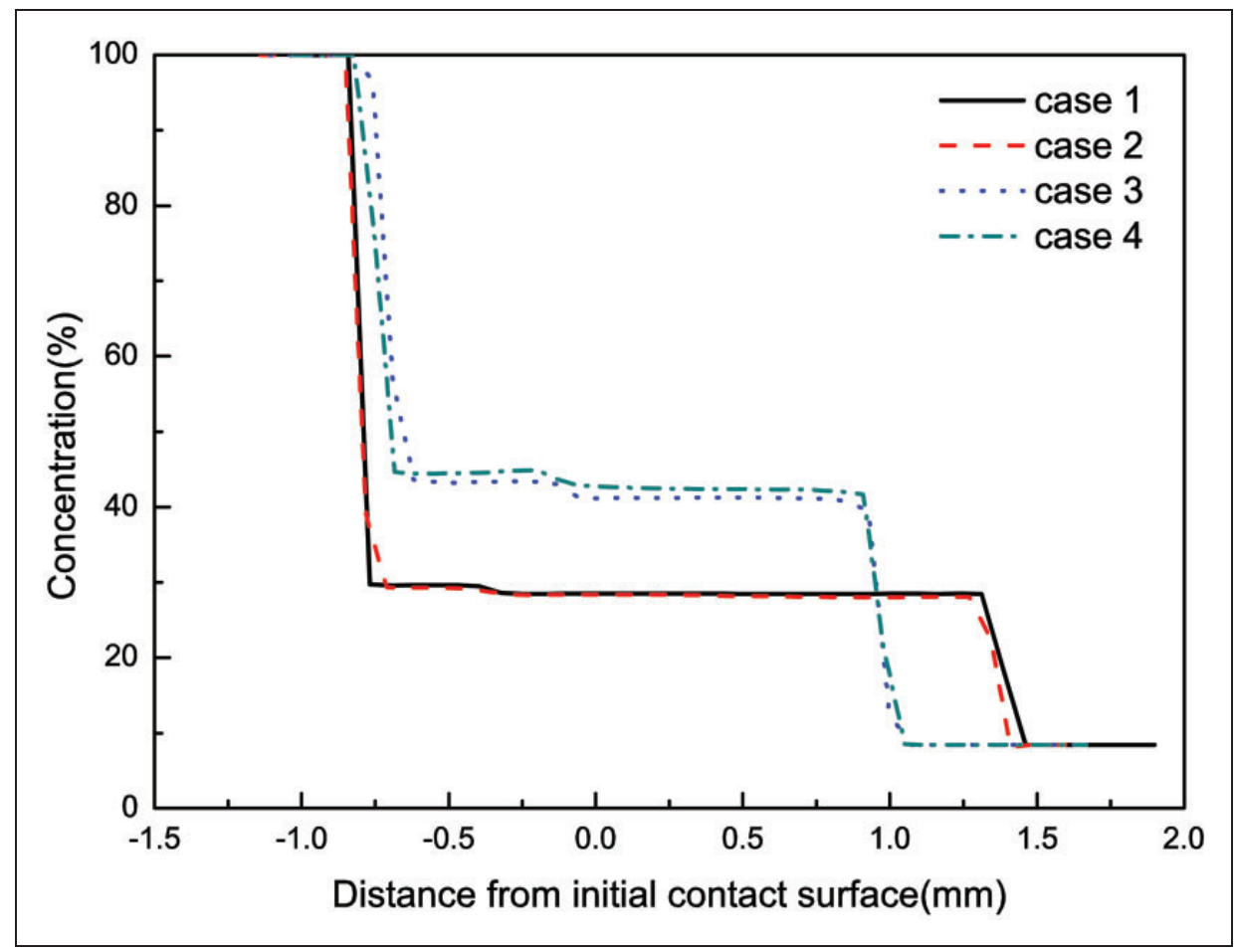

Figure 8. Concentration profiles of $\mathrm{Ni}$ at top surface at $500 \mathrm{~ms}$.

linearly dependent on the relative amounts of materials involved, the surface tension in the mixed weld pool mainly depends on that of SS. Under this assumption, although the temperature coefficients of $\mathrm{Ni}$ are different for case 4 (negative) and case 3 (positive), the temperature fields for the two cases are quite similar. It could be expected that the temperature field and dimension of weld pool mainly depend on the temperature coefficient of the metal which has lower thermal diffusivity, in laser butt welding of dissimilar couple. Relatively high concentration of these metals would control the resultant surface tension in the weld pool and then impose greater influence on heat transport by weld pool convection.

From Figure 8, as the temperature coefficient of SS changes from negative to positive, the concentration of $\mathrm{Ni}$ increases from 0.28 to 0.42 . Therefore, besides previously known factors, such as specific heat, thermal conductivity, and melting point, the temperature coefficient of surface tension is another important factor in determining the ratio of the molten part of the dissimilar couple. It could be expected that the 


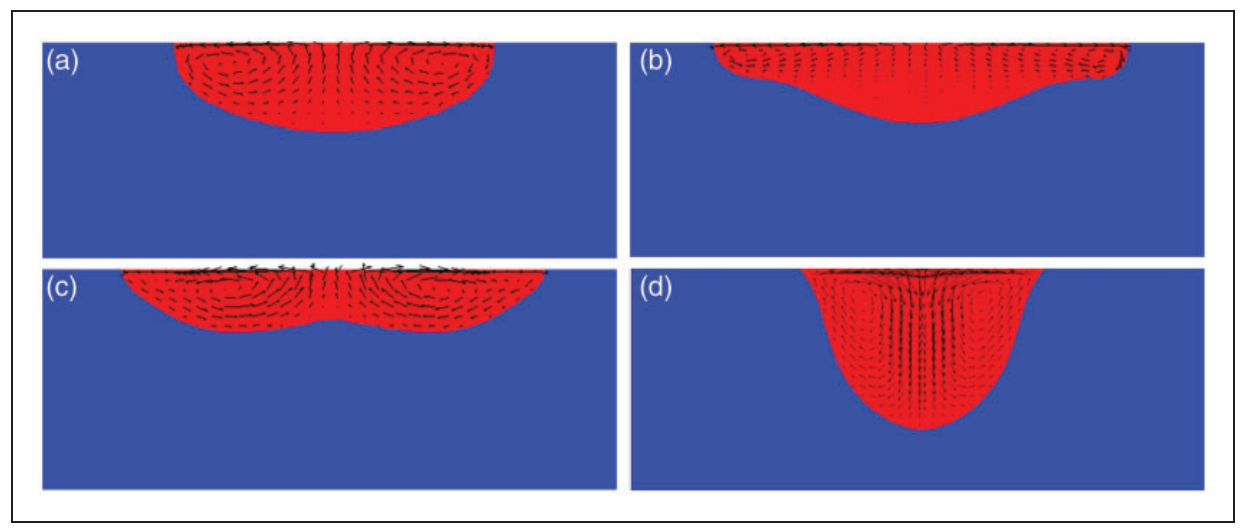

Figure 9. Various fusion boundary in similar welding under negative surface tension coefficient $(\mathrm{a}-\mathrm{c})$ and positive surface tension coefficient (d).

composition of element could be controlled to a certain level by changing the temperature coefficient of surface tension, so as to get the desirable microstructure of the weldment.

\section{Weld pool configuration}

The weld pool configuration could affect temperature gradient $(\mathrm{G})$, solidification growth rate $(\mathrm{R})$, and probability of the occurrence of solidification cracking, thus will have significant influence on the strength of the weldment. ${ }^{49}$ The discussion of the formation of weld pool boundary is given below.

The weld pool shape is different when the sign of temperature coefficient of surface tension changes. When the temperature coefficient of surface tension is negative, the fluid flows from the center of the weld pool to the periphery and greatly influences the heat transport inside the weld pool. Three kinds of weld pool shape are observed for welding of similar materials under negative temperature coefficient of surface tension, as schematically shown in Figure 9(a) to (c). Marangoni number and Prandtl number have been found to be the determining factors. ${ }^{50,51}$ The Marangoni number represents the ratio of surface tension gradient force to viscous force. If this number is small, convection is too weak to influence the weld pool shape and the fusion boundary will be hemispheric. Thermal conduction will be the major mechanism in heat transport. In the present investigation, Marangoni number is large enough to make convection an essential factor in heat transport. The Prandtl number, which represents the relative thickness of momentum and thermal boundary layers, is given by

$$
\operatorname{Pr}=\frac{\mu C_{p}}{K}
$$

Two types of fusion boundary could be observed for different Prandtl numbers, as shown in Figure 9(b) and (c). On the one hand, if the Prandtl number is small, convection mainly takes place in the upper part of the weld pool. The fusion boundary contains two inflexions of the slope of the boundary, ${ }^{52}$ as shown in Figure 9(b). The weld pool is enlarged by the outward flow. Marangoni eddies are located at the periphery of the weld pool. The inflexions of the slope of the boundary could be considered to be the watershed point of competing effects of thermal conduction and convection. The influence of convection on fusion boundary is limited to the upper part, and the bottom of the weld pool is concave dominated by heat conduction radially from the top surface. On the other hand, if the Prandtl number is large (e.g. $\operatorname{Pr}>1$ ), the thickness of momentum layer is larger than that of the thermal boundary, and the heat transport inside the weld pool will be largely influenced by the outward fluid flow. Marangoni eddies are located near the center part of the weld pool. The bottom of the weld pool will be convex, as shown in Figure 9(c). Heat transport by convection overweighs heat conduction and becomes the major mechanism for heat transport.

For positive temperature coefficients, the heat transport is different. A different wavy fusion boundary would be observed, ${ }^{39,53}$ as shown in Figure 9 (d). Fluid flows from the periphery of the weld pool to the center ("inward") and goes downward, increasing the weld pool depth and decreasing the weld pool width. The aspect ratio which defines the ratio of the depth of the weld pool to its width increases. Thus the welding depth could be increased by changing the sign of temperature coefficient of surface tension to be positive.

The wavy weld pool boundaries at both SS side and Ni side under negative (Figure 10(a) and (b)) and positive surface tension coefficients (Figure 10(c) and (d)) are quite similar to that shown in Figure 9(b) and (d), respectively, since the Prandtl number for 304 SS and $\mathrm{Ni}$ in the present investigation is about 0.25 and 0.028 , respectively. Typical fusion zones for laser spot welding of dissimilar metals (Ni and SS) under Ar shielding and Air shielding are shown in Figure 11. Under Ar shielding, temperature coefficient of surface tension of 


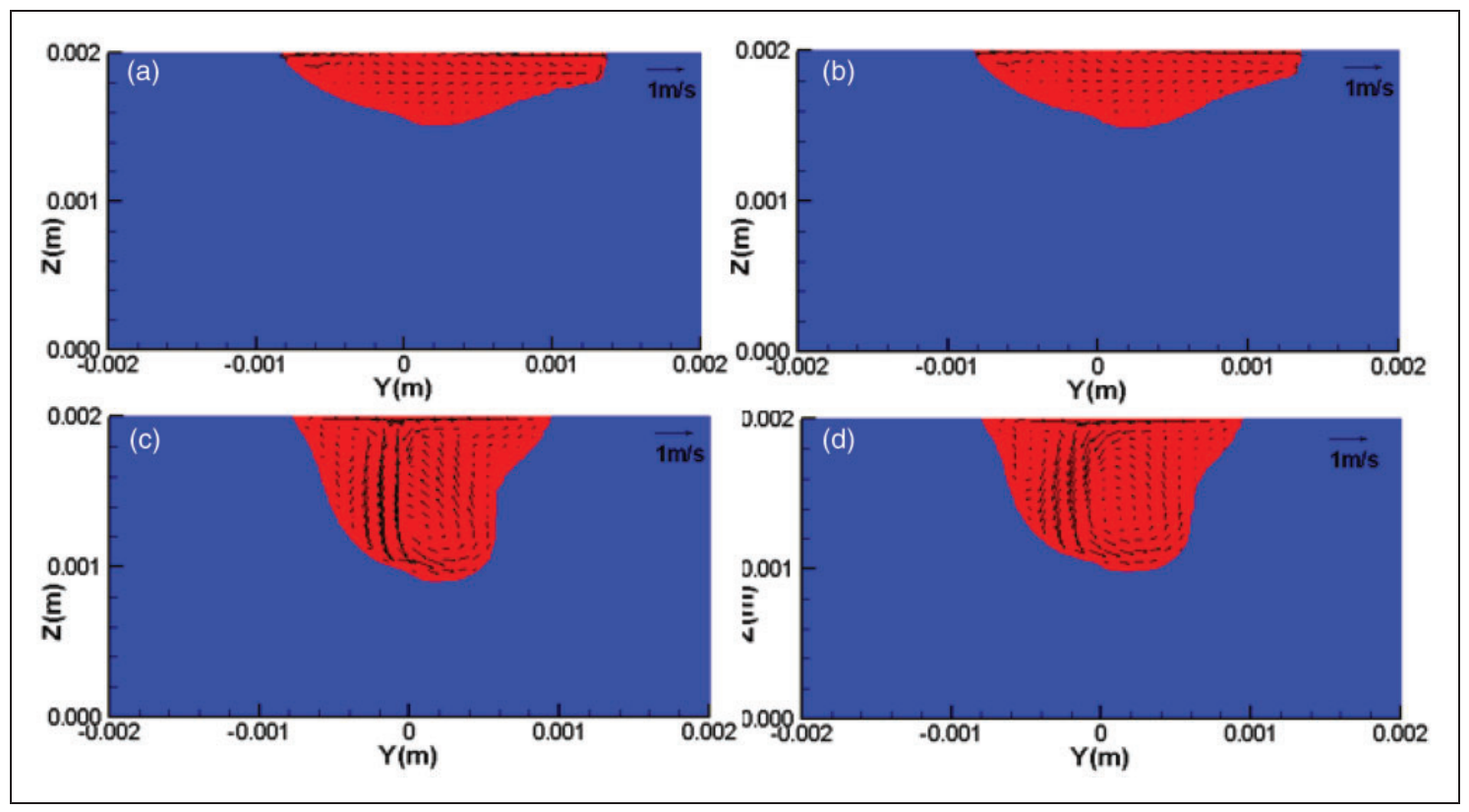

Figure 10. Calculated fusion boundaries for dissimilar welding (a) Case I, (b) Case 2, (c) Case 3, (d) Case 4.

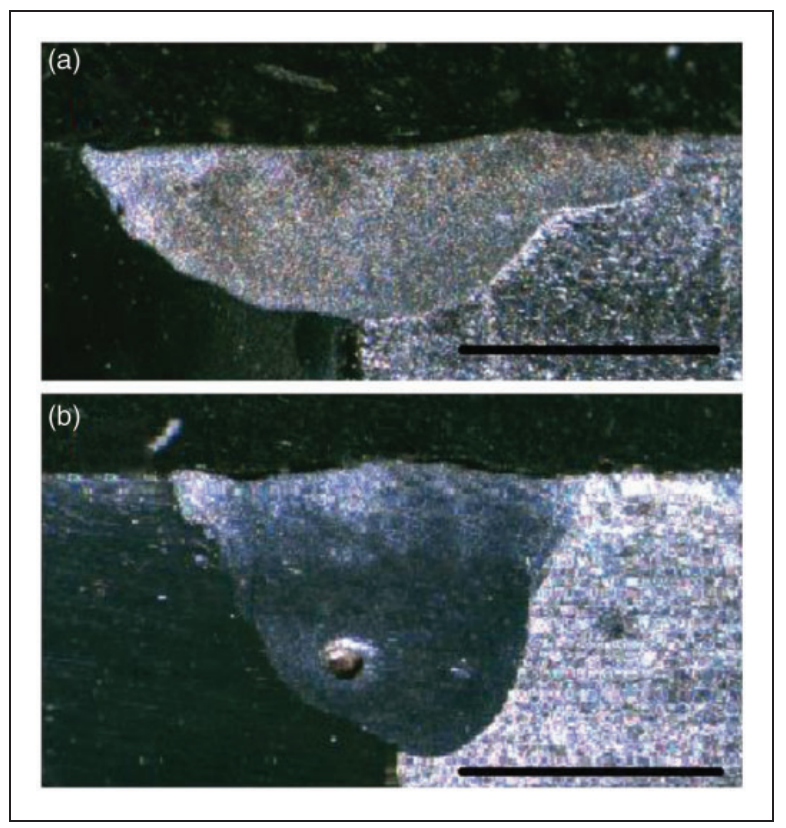

Figure I I. Optical images of typical fusion zone for laser spot welding of Ni (left) and SS (right) in Ar shielding (a) and in air shielding (b). Laser power: $650 \mathrm{~W}$; pulse duration: $500 \mathrm{~ms}$; spot diameter: $1.0 \mathrm{~mm}$. Scale bar: $1 \mathrm{~mm}$.

SS is negative. While under Air shielding, with oxygen serving as an surface active element, temperature coefficients would change to positive. ${ }^{39}$ It is shown under air shielding, the fusion zone has deeper penetration and smaller width than that under Ar shielding. The experimental results shown in Figure 11 (a) and (b) agree well with those calculated in Figure 10 (a) to (d) respectively. Sharp changes of curvatures of the fusion zone boundaries are due to competing effect of Marangoni flow and heat conduction. This feature would not be present if only heat conduction is considered and fusion zone would be hemisphere. The two distinct fusion zones during laser welding of dissimilar metals are due to different patterns of Marangoni flow which is governed by the temperature coefficients of the metals.

The weld pool configurations in dissimilar welding of SS and Ni in the present study could be understood through discussions of weld pool in welding of similar metals. However, in welding of other dissimilar metals, the elements mix up and properties of the liquid metal change as the weld pool develops. Further research of laser dissimilar welding under detailed control of temperature coefficients of surface tension to obtain desirable temperature field, element distribution, and fusion zone boundary will be taken out in the future.

\section{Summary}

Transport phenomena during pulsed laser butt welding of dissimilar couples have been studied by threedimensional transient numerical modeling of SS-Ni joining. According to the simulated results, the main conclusions can be summarized as follows:

1. Thermo-capillary convection due to temperature gradient is recognized as the dominating fluid flow. Marangoni stress due to concentration gradient $\left(\sigma_{\mathrm{c}}\right)$ acts as a driving force during the initial stage and its magnitude decreases quickly as the elements become uniformly mixed. After that, the influence of $\sigma_{\mathrm{c}}$ on heat and mass transport is relatively weak, and $\sigma_{\mathrm{T}}$ prevails and serves as the major driving force. 
2. The heat and mass transport in the weld pool is dramatically changed as the temperature coefficient of surface tension varies from negative to positive. Negative temperature coefficient of surface tension introduces low temperature gradient in the horizontal direction, while positive temperature coefficient of surface tension results in low temperature gradient at the vertical direction. The concentration of $\mathrm{Ni}$ increases from 0.28 to 0.42 as the temperature coefficient of SS changes from negative to positive. The influence of temperature coefficient of surface tension for two metals is different. The one with less thermal diffusivity has greater impact on transport phenomena in the weld pool.

3. The wavy weld pool boundary obtained in dissimilar welding is analyzed to be dependent on the Marangoni number, Prandtl number, and sign of temperature coefficient of surface tension. For negative temperature coefficient of surface tension, the bottom of the fusion zone boundary is concave because of small Prandtl numbers; and for positive temperature coefficient of surface tension, penetration depth increases and high aspect ratio weld pool is achieved under inward fluid flow. Experimental fusion zones agree well with that calculated from the model which considers different fluid flow patterns in the weld pool.

\section{Declaration of conflicting interests}

The author(s) declared no potential conflicts of interest with respect to the research, authorship, and/or publication of this article.

\section{Funding}

The author(s) disclosed receipt of the following financial support for the research, authorship, and/or publication of this article: This work was supported by National Natural Science Foundation of China under Grant No. 11272317 and 11272316.

\section{References}

1. Torkamany MJ, Tahamtan S and Sabbaghzadeh J. Dissimilar welding of carbon steel to 5754 aluminum alloy by Nd:YAG pulsed laser. Mater Des 2010; 31(1): 458-465.

2. Mohammadi $\mathbf{J}$, et al. Friction stir welding joint of dissimilar materials between AZ31B magnesium and 6061 aluminum alloys: microstructure studies and mechanical characterizations. Mater Charact 2015; 101: 189-207.

3. Evans WT, et al. Friction stir extrusion: a new process for joining dissimilar materials. Manuf Lett 2015; 5: 25-28.

4. Chen HC, Pinkerton AJ and Li L. Fibre laser welding of dissimilar alloys of Ti-6Al-4 V and Inconel 718 for aerospace applications. Int J Adv Manuf Technol 2011; 52(912): 977-987.

5. Sun $\mathrm{Z}$ and Ion JC. Laser-welding of dissimilar metal combinations. J Mater Sci 1995; 30(17): 4205-4214.

6. Yao $\mathrm{CW}$, et al. Interface microstructure and mechanical properties of laser welding copper-steel dissimilar joint. Opt Lasers Eng 2009; 47(7-8): 807-814.
7. Mathieu A, et al. Dissimilar material joining using laser (aluminum to steel using zinc-based filler wire). Opt Laser Technol 2007; 39(3): 652-661.

8. Chakraborty S, et al. Transport phenomena in conduction mode laser beam welding of $\mathrm{Fe}-\mathrm{Al}$ dissimilar couple with $\mathrm{Ta}$ diffusion barrier. Int $J$ Heat Mass Transf 2010; 53(23-24): 5274-5282.

9. Tamrin KF, et al. Determination of optimum parameters using grey relational analysis for multi-performance characteristics in $\mathrm{CO} 2$ laser joining of dissimilar materials. Opt Lasers Eng 2014; 57: 40-47.

10. Lazarevic S, et al. Experimental analysis of friction stir forming for dissimilar material joining application. J Manuf Process 2013; 15(4): 616-624.

11. Petrochenko PE, et al. Laser 3D printing with submicroscale resolution of porous elastomeric scaffolds for supporting human bone stem cells. Adv Healthc Mater 2015; 4(5): 739-747.

12. Gao H, et al. Large-scale nanoshaping of ultrasmooth 3D crystalline metallic structures. Science 2014; 346(6215): 1352-1356.

13. Esfahani MRN, Coupland $\mathrm{J}$ and Marimuthu $\mathrm{S}$. Numerical simulation of alloy composition in dissimilar laser welding. J Mater Process Technol 2015; 224: 135-142.

14. Zhao SS, et al. Microstructural and mechanical characteristics of laser welding of Ti6Al4V and lead metal. J Mater Process Technol 2012; 212(7): 1520-1527.

15. Ye C, et al. Bimodal nanocrystallization of NiTi shape memory alloy by laser shock peening and post-deformation annealing. Acta Materialia 2011; 59(19): 7219-7227.

16. Liao YL, et al. The mechanisms of thermal engineered laser shock peening for enhanced fatigue performance. Acta Materialia 2012; 60(13-14): 4997-5009.

17. Ye $\mathrm{CH}$, et al. Fatigue performance improvement in AISI 4140 steel by dynamic strain aging and dynamic precipitation during warm laser shock peening. Acta Materialia 2011; 59(3): 1014-1025.

18. Lin D, et al. Three-dimensional printing of complex structures: man made or toward nature? Acs Nano 2014; 8(10): 9710-9715.

19. Lee S, et al. Graphene laminated gold bipyramids as sensitive detection platforms for antibiotic molecules. Chem Commun 2015; 51(85): 15494-15497.

20. Kumar P, et al. Plasmonic tuning of silver nanowires by laser shock induced lateral compression. Nanoscale 2013; 5(14): 6311-6317.

21. Hu YW, et al. Water flattens graphene wrinkles: laser shock wrapping of graphene onto substrate-supported crystalline plasmonic nanoparticle arrays. Nanoscale 2015; 7(47): 19885-19893.

22. $\mathrm{Hu} \mathrm{YW}$, et al. Ultrafast direct fabrication of flexible substrate-supported designer plasmonic nanoarrays. Nanoscale 2016; 8(1): 172-182.

23. Nissim YI, et al. Temperature distributions produced in semiconductors by a scanning elliptical or circular $\mathrm{Cw}$ laser-beam. J Appl Phys 1980; 51(1): 274-279.

24. Ashby MF and Easterling KE. The transformation hardening of steel surfaces by laser-beams .1. hypoeutectoid steels. Acta Metallurgica 1984; 32(11): 1935.

25. Steen WM, et al. A point and line source model of laser keyhole Welding. J Phys D-Appl Phys 1988; 21(8): $1255-1260$. 
26. Postacioglu N, Kapadia P and Dowden J. A mathematical-model of heat-conduction in a prolate spheroidal coordinate system with applications to the theory of welding. $J$ Phys D-Appl Phys 1993; 26(4): 563-573.

27. Wu CS, Wang HG and Zhang YM. A new heat source model for keyhole plasma arc welding in FEM analysis of the temperature profile. Weld $J$ 2006; 85(12): $284 \mathrm{~s}-291 \mathrm{~s}$.

28. Gery D, Long H and Maropoulos P. Effects of welding speed, energy input and heat source distribution on temperature variations in butt joint welding. $J$ Mater Process Technol 2005; 167(2-3): 393-401.

29. Wu CS, Hu QX and Gao JQ. An adaptive heat source model for finite-element analysis of keyhole plasma arc welding. Comput Mater Sci 2009; 46(1): 167-172.

30. Sun JH, Wu CS and Feng YH. Modeling the transient heat transfer for the controlled pulse key-holing process in plasma arc welding. Int $J$ Therm Sci 2011; 50(9): 1664-1671.

31. Sharma A, et al. Estimation of heat source model parameters for twin-wire submerged arc welding. Int $J A d v$ Manuf Technol 2009; 45(11-12): 1096-1103.

32. Kiran DV, et al. Three-dimensional heat transfer analysis of two wire tandem submerged arc welding. Isij Int 2011; 51(5): 793-798.

33. Xu GX, et al. Numerical analysis of temperature profile and weld dimension in laser plus pulsed gas metal arc welding hybrid welding. Proc IMechE Part B: $J$ Engineering Manufacture 2011; 225(B4): 528-542.

34. Liang GL, Zhou G and Yuan SQ. Study on hybrid heat source overlap welding of magnesium alloy AZ31B. Mater Sci Eng a-Struct Mater Properties Microstruct Process 2009; 499(1-2): 93-96.

35. $\mathrm{Hu} \mathrm{Y}$, et al. Heat and mass transfer in laser dissimilar welding of stainless steel and nickel. Appl Surf Sci 2012; 258(15): 5914-5922.

36. He X, Fuerschbach PW and DebRoy T. Heat transfer and fluid flow during laser spot welding of 304 stainless steel. J Phys D-Appl Phys 2003; 36(12): 1388-1398.

37. Sahoo P, Debroy T and Mcnallan MJ. Surface-tension of binary metal-surface-active solute systems under conditions relevant to welding metallurgy. Metallurg Trans B-Process Metallurg 1988; 19(3): 483-491.

38. Wang Y, Shi Q and Tsai HL. Modeling of the effects of surface-active elements on flow patterns and weld penetration. Metallurg Mater Trans B-Process Metallurg Mater Process Sci 2001; 32(1): 145-161.

39. Lu SP, Fujii H and Nogi K. Sensitivity of Marangoni convection and weld shape variations to welding parameters in O-2-Ar shielded GTA welding. Scripta Materialia 2004; 51(3): 271-277.
40. Zhao CX, et al. The effect of oxygen on transitional Marangoni flow in laser spot welding. Acta Materialia 2010; 58(19): 6345-6357.

41. Zhao SS, et al. Numerical simulation and experimental investigation of laser overlap welding of Ti6Al4V and 42CrMo. J Mater Process Technol 2011; 211(3): 530-537.

42. Det al Deng. Predicting welding residual stresses in a dissimilar metal girth welded pipe using 3D finite element model with a simplified heat source. Nucl Eng Des 2011; 241(1): 46-54.

43. Aval HJ, Serajzadeh S and Kokabi AH. Thermomechanical and microstructural issues in dissimilar friction stir welding of AA5086-AA6061. J Mater Sci 2011; 46(10): 3258-3268.

44. Chung FK and Wei PS. Mass, momentum, and energy transport in a molten pool when welding dissimilar metals. J Heat Transf Trans Asme 1999; 121(2): 451-461.

45. Phanikumar G, Chattopadhyay $\mathrm{K}$ and Dutta $\mathrm{P}$. Modelling of transport phenomena in laser welding of dissimilar metals. Int J Numer Methods Heat Fluid Flow 2001; 11(2-3): 156-171.

46. Phanikumar G, Dutta P and Chattopadhyay K. Computational modeling of laser welding of $\mathrm{Cu}-\mathrm{Ni}$ dissimilar couple. Metallurg Mater Trans B-Process Metallurg Mater Process Sci 2004; 35(2): 339-350.

47. Chakraborty $\mathrm{N}$ and Chakraborty S. Modelling of turbulent molten pool convection in laser welding of a copper-nickel dissimilar couple. Int $J$ Heat Mass Transf 2007; 50(9-10): 1805-1822.

48. Chakraborty N. The effects of turbulence on molten pool transport during melting and solidification processes in continuous conduction mode laser welding of copper-nickel dissimilar couple. Appl Thermal Eng 2009; 29(17-18): 3618-3631.

49. Boüllinghaus T and Herold H. Hot cracking phenomena in welds. Berlin: Springer, 2005ix, 394p.

50. Arora A, Roy GG and DebRoy T. Unusual wavy weld pool boundary from dimensional analysis. Scripta Materialia 2009; 60(2): 68-71.

51. Wei PS, et al. The effects of Prandtl number on wavy weld boundary. Int J Heat Mass Transf 2009; 52(1516): 3790-3798.

52. Elmer JW, et al. Time resolved X-ray diffraction observations of phase transformations in transient arc welds. Sci Technol Weld Joining 2008; 13(3): 265-277.

53. Fujii $\mathrm{H}$, et al. Effect of oxygen content in He-O-2 shielding gas on weld shape in ultra deep penetration TIG. Sci Technol Weld Joining 2007; 12(8): 689-695. 